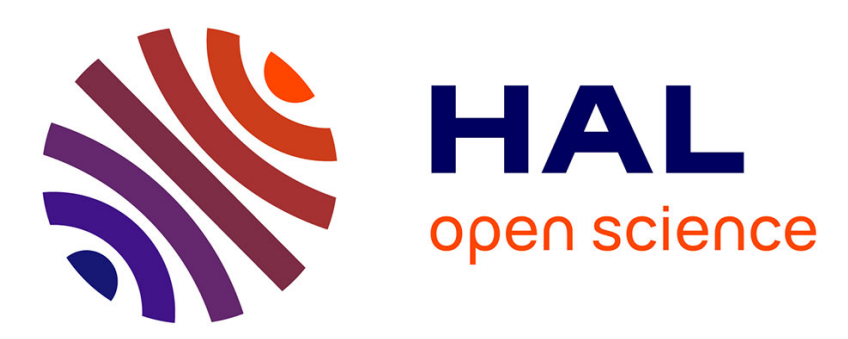

\title{
Experimental preforming of highly double curved shapes with a case corner using an interlock reinforcement
}

Samir Allaoui, Gilles Hivet, Damien Soulat, Audrey Wendling, Pierre Ouagne, Sylvain Chatel

\section{- To cite this version:}

Samir Allaoui, Gilles Hivet, Damien Soulat, Audrey Wendling, Pierre Ouagne, et al.. Experimental preforming of highly double curved shapes with a case corner using an interlock reinforcement. International Journal of Material Forming, 2014, 7 (2), pp.155-165. 10.1007/s12289-012-1116-5 . hal-00773212

\section{HAL Id: hal-00773212 \\ https://hal.science/hal-00773212}

Submitted on 11 Jan 2014

HAL is a multi-disciplinary open access archive for the deposit and dissemination of scientific research documents, whether they are published or not. The documents may come from teaching and research institutions in France or abroad, or from public or private research centers.
L'archive ouverte pluridisciplinaire HAL, est destinée au dépôt et à la diffusion de documents scientifiques de niveau recherche, publiés ou non, émanant des établissements d'enseignement et de recherche français ou étrangers, des laboratoires publics ou privés. 


\title{
Experimental preforming of highly double curved shapes with a case corner using an interlock reinforcement
}

\author{
S. Allaoui ${ }^{1}$, G. Hivet ${ }^{1}$, D. Soulat ${ }^{1}$, A. Wendling ${ }^{1}$, P. Ouagne ${ }^{1}$, S. Chatel ${ }^{2}$ \\ ${ }^{1}$ Laboratoire PRISME, UPRES EA 4229, Université d'Orléans, Polytech'Orléans, 8 \\ rue Léonard de Vinci 45072 Orléans Cedex 2, France \\ ${ }^{2}$ EADS France Innovation Works Structure Engineering Production and \\ Aeromechanics, Centre Technocampus EMC2, Allée du chaffault, F-44340 \\ Bouguenais, France
}

Corresponding author: Samir ALLAOUI, Laboratoire PRISME, UPRES EA 4229, Université d'Orléans,

Polytech'Orléans, 8 rue Léonard de Vinci 45072 Orléans Cedex 2, France. Tel : +33238494376. Fax : +33 2384173

29 - E-mail : samir.allaoui@univ-orleans.fr

\begin{abstract}
:
This experimental work concerns the study of the preforming of a specific highly double curved geometry with a triple point (case corner) by the sheet forming process using powdered interlock reinforcement $\left(\mathrm{G} 1151^{\circledR}\right)$. Three different punches (square box, prism, tetrahedron) were used in this study, each of them presenting highly double curved geometry with a case corner. A specific sheet forming device specially designed for the preforming of textile reinforcement was used. The expected shapes with the three punches have been obtained with an optimized blank-holder pressure. No classical defaults such as wrinkling or yarn damage are present in the useful zone of the preforms. However, a new default, not observed for spherical or hemispherical shape has been identified. It concerns the out of plane buckling of yarns. This phenomenon not observed on the square box is visible on some faces and edges of the prismatic and tetrahedron shapes. For the square box, it is easily possible to control the orientation of the yarn within the preform in the faces, whereas this is not possible for triangular faces
\end{abstract}


of the prismatic and tetrahedron shapes. The square box punch is therefore more adapted to preform the highly doubled curved shape with the case corner.

Keywords: Composites, RTM, Preforming, Sheet forming, Case corner, Defaults

\section{Introduction and context of the study}

Transportation industries are willing to replace metallic materials by composites materials on structural parts subjected to severe mechanical solicitations with equal mechanical performances. Composite materials are proposed because they are able to provide credible answers to the optimization of large and thick structural parts. Their good strength/weight ratio and especially their anisotropy which can be adapted to the mechanical solicitation of the structure are particularly interesting. Resin Transfer Molding (RTM) is one of the most important processing methods in the LCM processes family $[1,2]$. It is adequate for mass production of composite pieces with moderate cost compared to the traditional hand-layup or autoclaving and high fiber volume fractions, up to $60 \%$, are possible. Besides, the closed mould technique prevents hazardous styrene emission [3, 4]. During the forming step of very complex shapes significant deformations may occur resulting in local variation of the textile reinforcement geometry. These modifications of the reinforcement (homogeneity, fiber volume fraction, deformation state, ..) strongly influence the resin flow impregnation by the modification of the permeability components (longitudinal and transverse) [5-7]. They also influence the mechanical properties of the final composite part $[3,8,9]$. Numerical simulations have already been extensively used to investigate the viability of fabric forming by optimization of process control parameters, material selection and tool design to avoid production of costly prototypes. Some of these simulations describe the 
evolution of the dry reinforcement behaviour by mechanical approach [10-13]. These numerical works must be validated, compared and complemented by experimental results. Existing experimental fabric preforming studies are limited to low severity shapes such as hemispherical [9, 14-17] spherical [18], 3D deep drawing with conical tools [19] or a double dome preforming [11, 20-22]. From these studies, it is not possible to deduce the behaviour evolution of a fabric when complex shape forming with small curvature radius and a triple point is considered. In this paper an experimental analysis investigating the feasibility of obtaining very complex double curved dry preform is proposed.

A structural case corner part (Fig 1), manufactured up to now in aluminum, is at the basis of this study. This part is used to support the airplanes central box in aeronautical construction. It's a thick (about 16mm) part which has a very complex three-dimensional double-curved shape composed by three planar faces bound by a triple point (corner) and edges between each two planar faces. Sixteen plies are considered for the manufacture of the part by the RTM process, but this study concentrates on the feasibility to obtain a complex highly double curved shape with one ply. To manufacture such a part, by sheet forming, several punch geometries can be designed. Three of them are presented in figure 2.

During the forming process it is particularly essential to investigate:

- The presence of defects of any kind concerning the fabric in the useful part (fiber or yarn damage, wrinkles...etc) which may lead to a significant decrease of the composite performance. 
- The good homogeneity of local fiber density and the state of deformation of the woven reinforcement because it modifies the permeability of the fabric and consequently the resin flow during the injection step [5-7].

- The membranous orientation and position of the yarns within the layer with respect to the final shape because this gives the orientation of the stiffest direction of the obtained anisotropic layer.

A specific device presented into details in Section 2 has been developed at the lab in collaboration with EADS Company to reach this goal $[23,24]$. This device is also particularly interesting because the link between the mechanical behavior of the studied reinforcement and its formability can be carried out.

\section{Experimental procedures}

\subsection{Description of the forming device}

A specific device was developed in collaboration with EADS Company (Fig 3) to investigate the sheet forming of textile reinforcements. It is composed of a punch/open die couple which permits to obtain different double curvature shapes. The device is build so that any pair of punch/die can be adapted. The die is fixed and opened in order to measure and analyse the behaviour of the preform during the preforming stage $[18,24]$. The movement of the punch is conferred by an electric jack equipped with sensors in order to control and measure its position and speed but also to measure the force applied to the fabric. 
To avoid wrinkling defects during the preforming tests it is possible to introduce tension in the yarns. For that purpose the device is equipped by two systems. The first one is a classical multi-part blank-holder. It is composed of independent blank-holders actuated by pneumatic jacks that enable to impose and sensor independently a variable pressure. The system has been designed so that the number and the shape of the blank-holders can be easily changed to investigate the influence of the position and the pressure values on the preform properties. The second system used to apply tension to the fabric (not visible on Fig 3) is based on the drawbead principle. A low tension is applied on the yarn extremities so that the fabric does not show any wrinkles and any shear before applying the blank-holder pressure and before actuating the punch.

At the end of the preforming test, the realized dry preform can be fixed by applying a spray of resin on its surface so that the preform can be removed from the tools and stocked in the state corresponding to the end of the test. Global aspect (wrinkle, global dimensions ...) can be analyzed.

On complement and associated to these global information at the scale of the preform, it is important to measure local quantities such as the membranous positions, the orientations of the yarns but also the 3D strains of the fabric. In this intention, the device is equipped by 3D Digital Image Correlation system which is a noncontact measurement method $[25,26]$. Two numerical cameras are located at the top of the device. They can be positioned as a function of the specific zone of the fabric that has to be analyzed. For the computation of the displacement field, marks tracking technique is used $[8,27]$. A speckle pattern needs to be applied on the fabric surface, (Fig 4) before 
the test. They are carried out using white painting for dark fabrics and black painting for clear fabrics. A special care is given to this preparation, because markers must be as circular as possible and their diameter lower than the width of the yarns in order to avoid their deterioration during the test and thus disturb measurement [29]. The three space co-ordinates and thus the displacement field of these markers can be computed, using the marker tracking software Deftac 3D [28], from each digital image taken during the process and from the image captured at the reference state. With this $3 \mathrm{D}$ displacement field the membranous strains can be easily computed. Post processing treatments can be used to evaluate the mesoscopic behaviour of the fabric by considering only local markers. Yarn strains, yarn positions, shear angles ...etc can be computed. The evolution of the macroscopic behaviour, 3D geometry, appearance of defects ...etc) can also be investigated [24]. Whole of these measurements can be obtained for the final shape but their evolution during the forming process steps can also be measured.

2.2 presentation of the fabric used

The fabric used in this study is a powdered woven reinforcement used in aeronautics. It is denoted $\mathrm{G} 1151^{\circledR}$ and constituted by an interlock weaving of $6 \mathrm{~K}$ carbon yarns $\left(630 \mathrm{~g} / \mathrm{m}^{2}, 7.5 \mathrm{yarns} / \mathrm{cm}\right)$ (Fig 5). The fabric is manufactured by the Hexcel Company and its mechanical characteristics (tensile test, picture frame tests, bending tests, friction, ...etc) have been studied [30-35]. 


\subsection{Test conditions}

As indicated previously, this study concerns the feasibility of forming a case corner part by using three different punches (Fig 2). The first punch is a Prism with 280 $\mathrm{mm}$ length and $280 \mathrm{~mm}$ width. His total height is $175 \mathrm{~mm}$. The base height is $40 \mathrm{~mm}$. The dimensions of the square box punch are 280x280x280 $\mathrm{mm}^{3}$. For these two punches, an open square die $(300 \times 300 \mathrm{~mm})$ is used. The third punch is a tetrahedron form with $280 \mathrm{~mm}$ sides. His total height is $128 \mathrm{~mm}$ and the base height is $20 \mathrm{~mm}$. The die used with this punch is a triangular open die $\left(314 \times 314 \times 314 \mathrm{~mm}^{3}\right)$. The edges and vertices possess $10 \mathrm{~mm}$ radius for the three punches and $20 \mathrm{~mm}$ for the dies. Due to the low value of the edges radius, the expected shapes should be highly double curved and large strains are expected to take place along the edges. For each preforming test, one layer of G1151 ${ }^{\circledR}$ dry fabric $\left(\approx 0.9 \mathrm{~m}^{2}\right)$ is cut out. Markers are then positioned on the layers as indicated previously (Fig 4). The initial positioning of the fabric is of importance. This partly conditions the final yarns orientation within the part and as a consequence its mechanical stiffness. In the cases of the prismatic and the square box punches, the ply has been positioned with the weft and warp network parallel to the edges of the punches faces (detailed on Fig 6 and Fig 7). In the case of the tetrahedral punch, due to the geometry, it's more complex to place the fabric in order to foresee a specific orientation of the yarns in the final shape. For the tests presented in this paper, it was chosen (Fig 8) to align the warp and weft yarns with a symmetry plane of the tetrahedron. To ensure proper positioning of the fabric, one side of the outer three sides is taken as reference. The considered side is one that is parallel to the sides of the fabric ply (at left on the figure). When positioning the fabric, the weft yarns are aligned on this side with respect 
to the open die, when the warp yarns are perpendicular and passé through the opposite corner. A set-square is used to ensure this position.

However for all the tests realized with different punches, the angle between the weft and warp yarns are controlled using set-square and the optical measurement in order to ensure that the fabric handling do not generates shearing before forming. The measured initial angles are around $90^{\circ} \pm 0.5$.

Before applying the blank-holder pressure, and before starting the movement of the punch, the fabric can bend under its own weight. It is therefore necessary to apply some tensions at the yarn extremities using the drawbead system. Rectangular or square blank-holder can be placed along each edges and corners of the punch. Height rectangular blank-holders were used for the prismatic and square box punches whereas only six of them were used for the tetrahedron (Fig 6, 7,8). The pressure was then applied on each of them. For these tests the punch velocity is $30 \mathrm{~mm} / \mathrm{min}$ and its stroke $160 \mathrm{~mm}$. For each punch, at least of three tests were carried out. The results and discussions obtained on the different shapes are exposed and discussed below.

\section{Results and discussion}

3.1 Optimization of the blank-holder pressure on the preforming step First, tests at different blank-holder pressures were carried out in order to determine the optimized pressure to use for the interlock fabric forming. Figure 9 presents the different shapes obtained with the prismatic punch that is highly non-expandable with small curvature radii (10mm). The global shape (Fig 9. a, b, c) looks globally correct. In the useful zone, with a low blank-holder pressure ( 0.2 bar) some few wrinkles (Fig 9.d) 
appear. However, these ones disappear once the pressure reaches a value of 1 bar (Fig 9.e). Wrinkles are visible around the useful zones and especially near the position of the blank-holders. These non-useful zones are cut after the process. Consequently, these wrinkles have no consequences on the quality of the performs, but, these results confirm first the influence of the tension in yarns, due to the blank-holder pressure, on the presence of wrinkle and second the necessity to apply some load to obtain a preform without default [13].

For a constant blank-holder pressure of 1 bar, Figure 10 shows the comparison of the macroscopic shapes obtained with the three different punches. The global three shapes obtained do not show any obvious default such as wrinkling or yarn damage as long as a minimum blank-holder pressure is applied.

To form complex shapes such as the one presented in Figure 10, the fabric may accommodate large in-plane shear deformation. It was shown that the $\mathrm{G} 1151^{\circledR}$ fabric is particularly adapted to this deformation mode, with a high value of the locking angle $\left(\sim 55-60^{\circ}\right)[31,32]$. However, the only notion of locking angle is not sufficient to anticipate the presence of wrinkles. Indeed, a rise of the blank-holder pressure has the tendency to delay the appearing of wrinkles. This means that it is possible to obtain high shear deformation where the shear angle is higher than the locking angle if tension is applied to the fabric. This confirms the importance of the coupling between shear and tension as already discussed in $[32,36]$.

In the global analysis of the realized preforms, no defaults such as broken yarns have been noticed even for the highest blank-holder pressure tests. From a uniform pressure 
$\mathrm{P}$ applied on a number of yarn by unit length, denoted $\mathrm{d}$, positioned on a width 1 , it can be deduced, in first approximation, the tension load, $\mathrm{f}$, if the friction coefficient between the tool/fabric, $\mu$ is known by Equation 1:

$$
f=\frac{\mu P l}{d}
$$

In the case of an interlock which has 7.5 yarns per $\mathrm{cm}$, thus $\mathrm{d}=0.75 \mathrm{yarns} / \mathrm{mm}$. The tool/fabric Coulomb friction factor has been determined using a specific device [35] according to the protocol defined in [37]. Its value is $\mu=0.17$ With $\mathrm{P}<6$ bar (device limit) applied on $\mathrm{l}=100 \mathrm{~mm}$ (dimension of the blank-holder) the maximum force applied to each yarn is given by Equation 2:

$$
f=\frac{0.173 * 0.6 * 100}{0.75}=13.6 \mathrm{~N} / \text { yarn }
$$

In comparison to the mechanical behavior of the fabric in tension, this value is very far from the tensile limit of the carbon yarns. To confirm that fact, tensile tests were carried out on yarns extracted from the dry fabric before and after shaping. Yarns extracted after forming were pull out from those passing by the shapes because they are subjected to highest mechanical stress. Specimen's length is $250 \mathrm{~mm}$ and the cross head speed is $20 \mathrm{~mm} / \mathrm{min}$. Figure 11 shows that the yarns behaviour and the maximum strength were not affected. Before yarns breaking, we notice a load drops that are probably due to the damage occurs by weaving process since that take place on the two groups of yarns. It can be concluded that for this carbon fabrics, the rise of the blank-holder pressure does 
not lead to yarn damage. However, for others nature of yarns (glass, natural fibers, comingled yarns,...) this type of default may occur.

Figure 12 details the preforms obtained from the tetrahedron punch with a high blank-holder pressure equal to 4 bars. No defaults such as wrinkles or yarns damage are observed. However, increasing the blank-holder pressure leads to high tensions in the fabric, and "weave pattern heterogeneity" of the reinforcement, near the base of the shape can be visible. This local "weave pattern heterogeneity" is caused by a relative slip of the weft and warp yarns and leads to a very low local yarn density. It's obviously an unacceptable defect for the preform and its homogeneity. Due to the high pressure of the blank-holder the reinforcement is subjected to different tensions in the two yarns direction probably at the origin of the default. The tension exerted by the blank-holder, through the friction, on one yarn network is greater than that exerted by the transverse yarns network, through the yarn/yarn pressure via friction, which ensures the cohesion of the architecture. This type of default depends mainly on the complexity of the shape, the boundary condition as well as the cohesion of the fabric weaving. Moreover, this phenomenon was observed in the lab for a glass plain weave fabric on the prismatic punch for only 1 bar of blank-holder pressure (Fig 13). This result shows the importance to control the blank-holder pressure for complex preform. Some wrinkles can occur with too weak pressure or disappear with an adequate value, but an excessive pressure can lead to another default such as "weave pattern heterogeneity". To understand this phenomenon it's necessary to develop a specific test independently of the process. 


\subsection{Position of the yarn after forming}

In this work, three punches are used to study the feasibility of forming a double curved part with a triple point. It is expected that the deformation modes and magnitudes are different according to the punch used. In this Section, it is proposed to investigate the orientation of the yarns after forming because this parameter controls the mechanical aptitudes of the final part as well as the permeability of the preform.

Figure 10 shows results obtained from the experimental forming of the interlock weave with the three punches under 1 bar of blank-holder pressure. In Figure 14, schematic diagrams describe the final yarn orientations for the three performs at several locations.

First, an analysis of yarn positions on the two rectangular faces for the prismatic punch and the five rectangular faces, for the square box is conducted. The fabric yarns, on all these faces, keep good orientation homogeneity. The yarns network is parallel to all the shape edges as expected with the choice of the initial position of the fabric. These results are confirmed with the measurements of the shear angle obtained with the mark tracking software Deftac 3D (Fig 15 for the square box; Fig 16 for the prismatic punch). Since the weaving network remains parallel, the shear angle remains low with a maximum of $5.3^{\circ}$ for the square box and $2.6^{\circ}$ for the prismatic punch. Controlling the homogeneity of the yarns position and of the shear deformation state allow, in these zones, to predict a good homogeneity of the fiber volume fraction and consequently of the mechanical properties. On the lateral edge, for the square box, or at the base corners for the three shapes, the shear deformations are more complex. Due to the little edges radius value for the square punch and the very deep shaping (Fig 15), high shear angles have been reached $\left(\sim 50-60^{\circ}\right)$ and are close to the locking angle of the $\mathrm{G} 1151^{\circledR}$ identified 
during a shear test $[31,32]$. High levels of shear deformation were also measured for the prismatic shape $40^{\circ}$ to $50^{\circ}$ and $50^{\circ}$ to $60^{\circ}$ for the tetrahedron one at the basis of each corner (Fig 17). In these small zones the fabric must accommodate the brutal change of the punch geometry and is submitted to the pressure of the blank-holder. For the fabric tested, this high shear deformed state does not conduct to default, in theses location, but will affect the injection step.

The last zones to analyze concern the triangular faces of the prismatic shape (two lateral faces) and the three tetrahedron faces. The yarns networks do not remain parallel to the edges of the punches (Fig 16,17). For the prismatic shape the weft yarns network initially parallel to the edges (Fig 14.b) become curved, and for the tetrahedron the phenomenon is the same but concerns the weft or the warp yarns depending on the observed faces. These specific obtained orientations depend on the geometry of the shape, the initial positioning of the fabric, but also the position of the blank-holder. The measurement of the shear angle on these triangular faces, for the two shapes (Fig 16, 17) confirm that the shear deformation in the fabric is more important comparatively to others faces, due to the curved yarns. On both sides of the yarns passing by the top of this shape, two symmetrical zones can be visible where the shear angle is relatively the same (respectively $\sim 24.5^{\circ}$ for the tetrahedron shape and $\sim 41.2^{\circ}$ for the prismatic one). For the tetrahedron punch, the evolution of the fabric shear angle on a triangular face during the process is presented in figure 18. It can be concluded that the maximum angle is reached and remains constant quite before the end of the process.

Controlling the final yarns orientation is easily possible on rectangular or square faces with the prismatic or square box punches. For the triangular faces of the prismatic 
shape as well as for the face of the tetrahedron faces, the orientation of the yarns is more difficult to control with regard to the desired final shape and which should meet the specifications in terms of mechanical solicitation.

\subsection{Out of plane buckles}

When using the tetrahedron and the prismatic punches, another type of defect denoted by out of plane buckles appears on faces and on some edges of the preforms (Fig 19). Locally these buckles constitute a consequent over thickness, which can reach $3 \mathrm{~mm}$ of height near the triple point. Consequently the homogeneity of the thickness's preform is not controlled. As described on figures 19.a, b theses buckles are localized on zones of about 15 to $35 \mathrm{~mm}$ width. On the tetrahedron, these buckles zones are present, at least, on each triangular faces and edges which converge to the triple point (top of the shape) from the bottom of the shape. On the prismatic shape, the buckles are localized on the triangular faces, at the middle of the face but also on the diagonal edges, separating the triangular to the rectangular faces. At the reinforcement level, buckles are one out-of plane default. It can be compared to the wrinkling phenomenon but this one takes place at the scale of the fabric, whereas buckling takes place at the scale of yarns. It could be assimilated to the buckling of yarns and is not the same like that has been described for NCF reinforcement like an in-plane buckling [17].

The experimental observations show that yarns passing by the triple point are subjected to consequent tensile deformation. The yarns perpendiculars to these ones are not so much tightened. On both sides of the buckles zones, especially on triangular faces, the yarns perpendicular to the one passing by the triple point are curved as already mentioned in Section 3.2. These yarns try to accommodate bending in their plane. It 
seems that this is not possible and out of plane bending takes place. The buckles localization and size depends on the tension of the yarn perpendicular to the one passing by the triple point and therefore on the blank-holder pressure. The influence of each process parameters used during the forming of the considered reinforcement on the apparition and the quantification of these buckles will be the subject of futures works. The architecture of the reinforcements should probably be investigated with the goal to optimize the constitution of the fabric to avoid the generation of buckles.

\section{Conclusion :}

This experimental work concerns the study of the preforming of a specific, highly double curved geometry with a triple point (case corner) by the sheet forming process. The criteria necessary for obtaining a preform without defaults from specific interlock reinforcement $\left(\mathrm{G} 1151^{\circledR}\right)$ have been investigated. Three different punches (square box, prism, tetrahedron) were used in this study, each of them presenting highly double curved geometry with a case corner. A specific sheet forming device specially designed for the preforming of textile reinforcement was used. This device can be used of course to preform reinforcements, but also to analyze defaults at the level of the preform (wrinkles, yarn damage....) as well as at the local scale (yarn position after forming, shear angles...). The preforming criteria investigated in this work concern the type of the punch but also all the involved process parameters such as the blank-holder pressure for example. At the scale of the preform the influence of the pressure applied by the blank-holder has been analyzed. These loads are necessary to prevent default, such as wrinkles, but too high values can conduct to others defaults such as "weave pattern heterogeneity“ due to yarn slipping. This phenomenon should be identified from 
specific tests, independently of the preforming process so that the influence of the constitution of the reinforcement in the apparition of the defaults is taken into account. The expected shapes with the three punches have been obtained on the condition an optimized blank-holder pressure is applied. No classical defaults such as wrinkling or yarn damage are present in the useful zone of the preform. This is particularly the case for the square box preform. Even if high shear angles above the locking angle are observed in the corners $\left(\sim 50-60^{\circ}\right)$ no wrinkle appear. This means that the knowledge of the only shear behavior is not sufficient to predict the appearing of wrinkles because this defects is the consequence of combined phenomena involving all strains and rigidities taking place within the fabric (tension, in-plane shear, bending).

A new default, not observed for spherical or hemispherical shape has been identified as out of plane buckling of yarns. This phenomenon not observed on the square box is visible on some faces and edges of the prismatic and tetrahedron shapes. The mechanisms at the origin of buckling are not fully understood and should be identified from specific tests, independently of the preforming process to study the influence of the reinforcement architecture in relation to this default.

The homogeneity and the orientation of the yarn after preforming have also been investigated. For the square box, it is easily possible to control the orientation of the yarn within the preform in the faces, whereas this is not possible for triangular faces of the prismatic and tetrahedron shapes.

From the previous paragraph, it therefore seems that the square box punch is the most adapted to realize the highly double curved preform with a case corner from the G1151 ${ }^{\circledR}$ interlock reinforcement even if high shear take place in the corner therefore reducing 
locally the permeability of the preform. For the two others punches another architecture of fabric should be envisaged.

From the reinforcement point of view, this work has shown that the orientation of the yarn as well as buckling or "weave pattern heterogeneity" (yarn slipping) are essential parameters to take into account as much as the shear angle which remains the most studied in the literature as mechanism inducing defaults. The control and the optimization of the process parameters are also essential to realize complex shape preforms. In this work, experimental approaches are used to first identify all the phenomena taking place during preforming before eventually using the results for the numerical approaches. In future works a parametric study with one and several plies will be conducted to take into account the variation of all the parameters relatively to each other.

\section{Acknowledgements}

The work reported here has been carried out in the scope of the project LCM3M (ANR,

French National Research Agency) and has been supported by EADS IW company.

\section{REFERENCES}

1. Advani SG (1994) Flow and rheology in polymeric composites manufacturing. Elsevier, ISBN0 444893474.

2. Rudd CD, Long AC (1997) Liquid molding technologies. Woodhead Publishing Limited.

3. S. H. Lee, J.H. Han, S.Y. Kim, Jae R. Youn, Y. S. Song (2010) Compression and Relaxation Behavior of Dry Fiber Preforms for Resin Transfer Molding. J. Compos. Mater. 44(15):1801-1820.

4. W.D. Brouwer, E.C.F.C. Van Herpt, M. Labordus (2003) Vacuum injection moulding for large structural applications. Composites Part A 34:551-558

5. Arbter, R., Beraud, J.M., Binetruy, C., Bizet, L., Bréard, J., Comas-Cardona, S., Demaria, C., Endruweit, A., Ermanni, P., Gommer, F., Hasanovic, S., Henrat, P., Klunker, F., Laine, B., Lavanchy, S., Lomov, S.V., Long, A., Michaud, V., Morren, G., Ruiz, E., Sol, H., Trochu, F., Verleye, B., Wietgrefe, M., Wu, W., Ziegmann, G. (2011) Experimental Determination of the 
Permeability of Textiles: A Benchmark Exercise. Composites Part A 42(9):1157-1168.

6. Heardmann E., Lekakou C., Bader M.G. (2001) In plane permeability of sheared fabrics. Composites Part A 32: 933-940.

7. P. Ouagne, J. Bréard. (2010) Continuous transverse permeability of fibrous media. Composites Part A 41 (1):22-28.

8. Prodromou AG, Chen J. (1997) On the relationship between shear angle and wrinkling of textile composite preforms. Composites Part A 28:491-503.

9. A.A. Skordos, C.M. Aceves, M.P.F. Sutcliffe (2007) A simplified rate dependent model of forming and wrinkling of pre-impregnated woven composites. Composites Part A 38: 1318-1330.

10. S.G. Hancock, K.D. Potter (2006) The use of kinematic drape modelling to inform the hand lay-up of complex composite components using woven reinforcements. Composites Part A 37:413-422.

11. Peng XQ, Rehman ZU (2011) Textile composite double dome stamping simulation using a non-orthogonal constitutive model. Compos. Sci. Tech. 71(8): 1075-1081

12. N. Hamila, P. Boisse (2008) Simulations of textile composite reinforcement draping using a new semi discrete three node finite element. Composites B 39: 999-1010.

13. Boisse, P., Hamila, N., Vidal-Sallé, E., Dumont, F. (2011) Simulation of wrinkling during textile composite reinforcement forming. Influence of tensile, in-plane shear and bending stiffnesses. Compos. Sci. Tech. 71 (5): 683-692.

14. P.A. Kelly, S. Bickerton (2009) A comprehensive filling and tooling force analysis for rigid mould LCM processes. Composites A 40(11):1685-1697.

15. H. Lin, J. Wang, A.C. Long, M.J. Clifford, P. Harrison (2007) Predictive modelling for optimization of textile composite forming. Compos. Sci. Tech. 67:3242-3252.

16. Mohammed U, Lekakou C, Bader MG (2000) Experimental studies and analysis of the draping of woven fabrics. Composites A 31(12):1409-20.

17. Lee J., Hong S., Yu W., Kang T (2007) The effect of blank holder force on the stamp forming behavior of non-crimp fabric with a chain stitch. Compos. Sci. Tech. 67(3-4):357-366

18. R.M.J.S. Sidhu, R.C. Averill, M. Riaz and F. Pourboghrat (2001) Finite element analysis of textile composite perform stamping, Compos. Struct. 52(34):483-497.

19. A. Cherouat, H. Borouchaki, L. Giraud-Moreau (2010) Mechanical and geometrical approaches applied to composite fabric forming. Int. J. Mater. Form. 3(2):1189-1204.

20. Woven Composites Benchmark Forum. http://www.wovencomposites.org

21. M.A. Khan, T. Mabrouki, E. Vidal-Sallé, P. Boisse (2010) Numerical and experimental analyses of woven composite reinforcement forming using a hypoelastic behavior: Application to the double dome benchmark. J. Mater. Process. Technolo. 210:378-388.

22. K. Vanclooster, S.V. Lomov, I. Verpoest (2009) Experimental validation of forming simulations of fabric reinforced polymers using an unsymmetrical mould configuration. Composites A 40:530-539. 
23. S. Allaoui, P. Boisse, S. Chatel, N. Hamila, G. Hivet, D. Soulat, E. Vidal-Salle (2011) Experimental and numerical analyses of textile reinforcement forming of a tetrahedral shape. Composite A 42(6): 612-622.

24. S. Allaoui, J. Launay, D. Soulat, S. Chatel (2008) Experimental tool of woven reinforcement forming. Inter. J. Mater. Form. 2(1): 815-818.

25. Dumont F, Hivet G, Rotinat R, Launay J, Boisse P, Vacher P (2003) Field measurements for shear tests on woven reinforcements. Mecanique et Industrie 4:627-635.

26. Willems A, Lomov SV, Verpoest I, Vandepitte D (2008) Optical strain fields in shear and tensile testing of textile reinforcements. Compos. Sci. Tech. 68:807-819.

27. Launay J., Lahmar F., Boisse P., Vacher P (2002) Strain measurement in tests of fibre fabric by image correlation method. Adv. Compos. Letters 11(1):7-12.

28. Bretagne N., Valle V., Dupré JC (2005) Development of the marks traking technique for strain field and volume variation measurements, NDT\&E International 38(4): 290-298.

29. Bremand, F., Dupre, J.C., Lagarde, A (1995) Mesure de déformations sans contact par analyse d'images. Proceedings of Photomechanics :171-177.

30. Cao J, Akkerman R, Boisse P, Chen J, et al. (2008) Characterization of mechanical behavior of woven fabrics: Experimental methods and benchmark results. Composites A 39(6):1037-1053.

31. Hivet G., Duong AV (2011) A contribution to the analysis of the intrinsic shear behaviour of fabrics. J. Compos. Mater. 45(6):695-717.

32. Launay J., Hivet G., Duong AV, Boisse P (2008) Experimental analysis of the influence of tensions on in plane shear behaviour of woven composite reinforcements. Compos. Sci. Techn. 68(2):506-515.

33. Anh Vu Duong (2008) Étude expérimentale du comportement mécanique de renforts composites tissés lors de la mise en forme sur géométrie non développables. $\mathrm{PhD}$ thesis, Université d'Orléans.

34. De Bilbao E, Soulat D, Hivet G, Gasser A (2010) Experimental study of bending behaviour of reinforcements. Exp. Mech. 50:333-51.

35. S. Allaoui, G. Hivet, A. Wendling, P. Ouagne, D. Soulat (2012) Influence of the dry woven fabrics meso-architecture on fabric/fabric contact behaviour. J. of Composite Material 46(6):202-210.

36. S.V. Lomov SV, Verpoest I (2006) Model of shear of woven fabric and parametric description of shear resistance of glass woven reinforcements. Compos. Sci. Tech. 66(7-8):919-933.

37. U. Sachs, K. Fetfatsidis, J. Schumacher, G. Ziegmann, S. Allaoui, G. Hivet, E. Vidal-Sallé and R. Akkerman (2012) A friction-Test Benchmark with Twintex PP, Key engineering materials 504-506:313-318. 


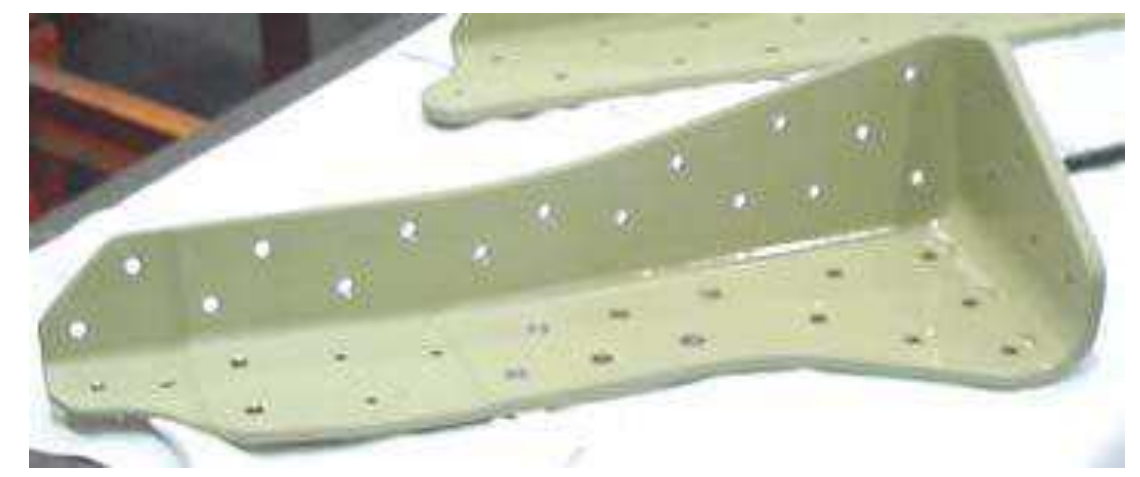

Fig 1: Case corner part used for aeronautical application

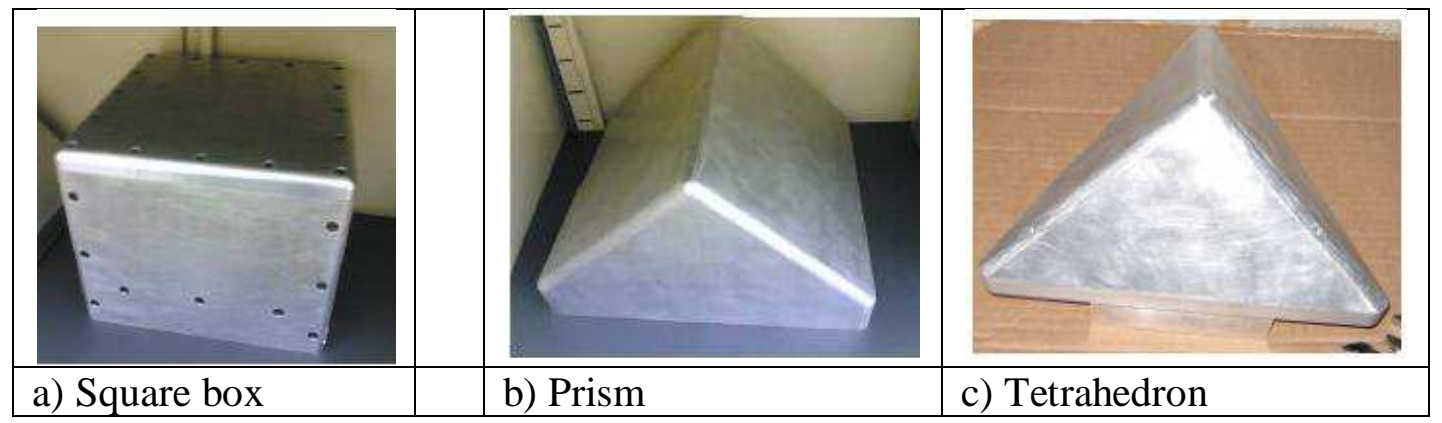

Fig 2: Punches 


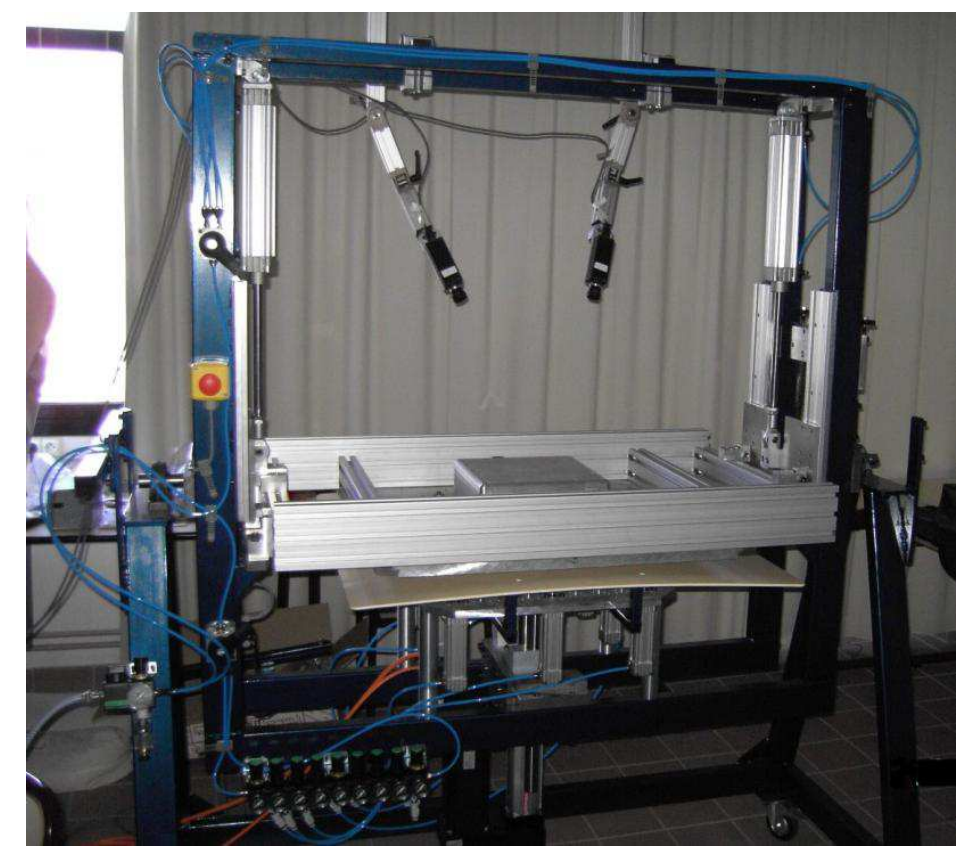

Fig 3: The sheet forming device

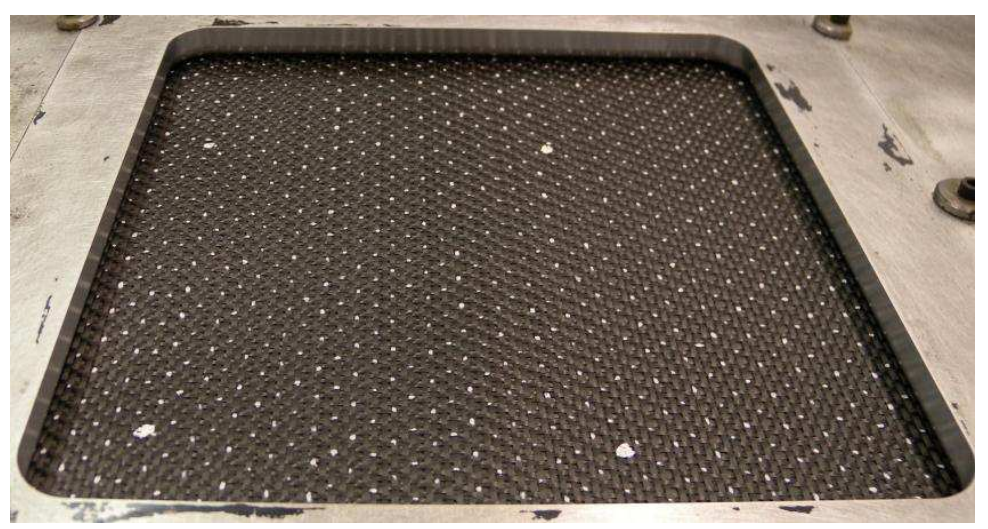

Fig 4: Carbon reinforcement with markers at the initial state 


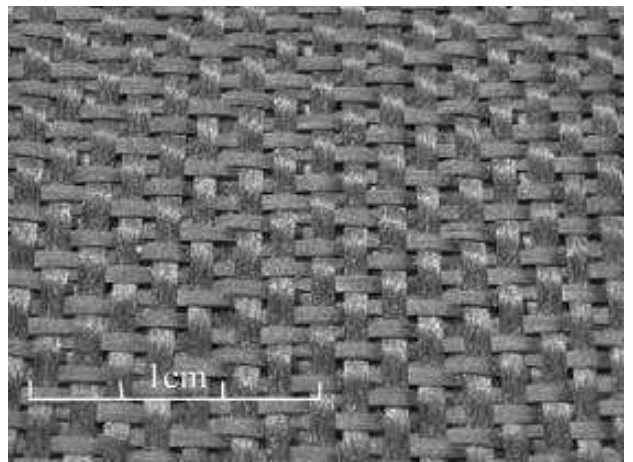

Fig 5: Woven interlock carbon reinforcement $\left(\mathrm{G} 1151^{\circledR}\right)$

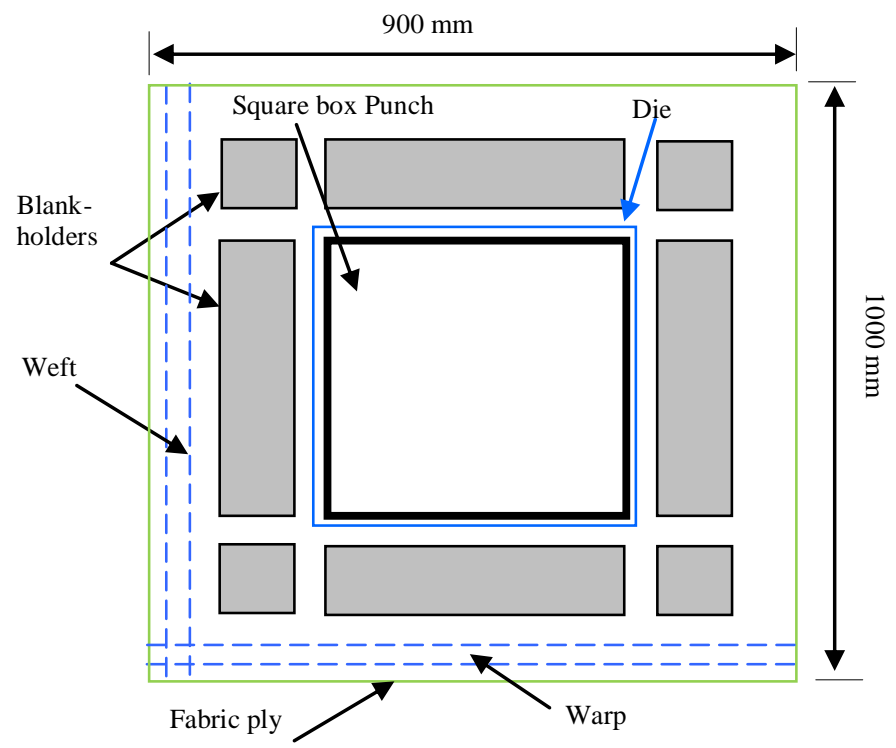

Fig 6: Initial positioning of the interlock fabric for the square box punch. 


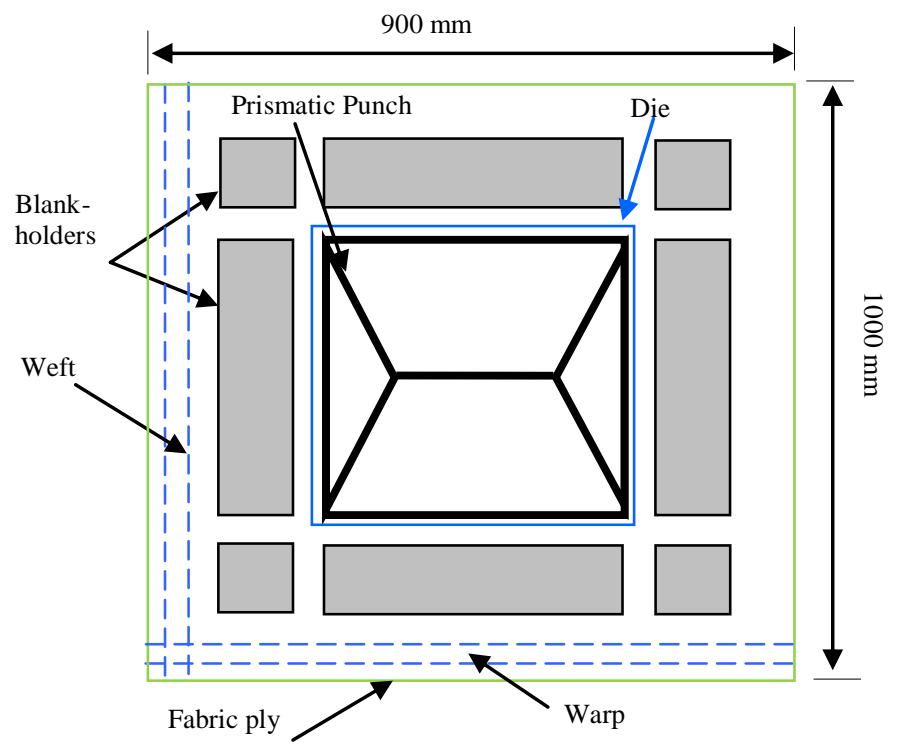

Fig 7: Initial positioning of the interlock fabric for the prismatic punch.

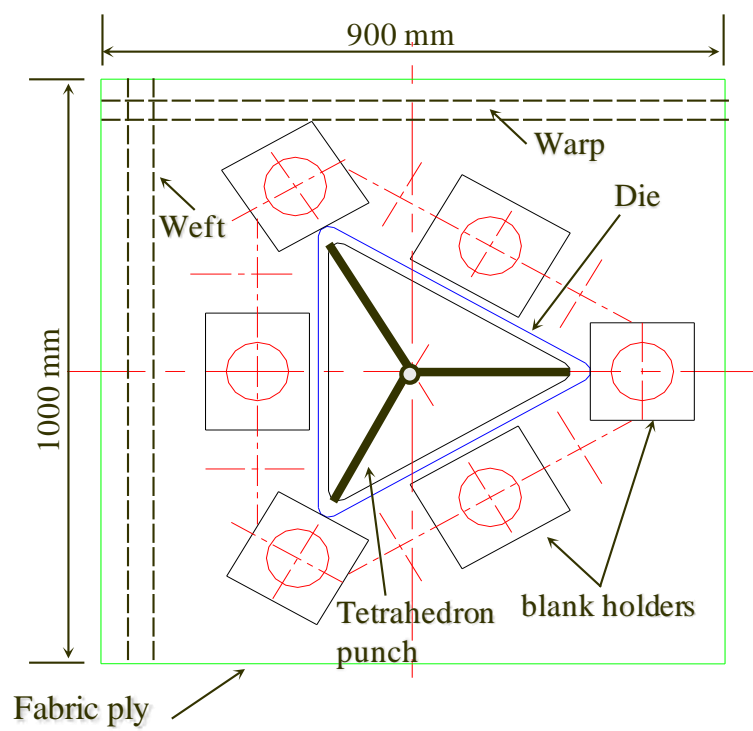

Fig 8: Initial positioning of the interlock fabric for the tetrahedron punch. 

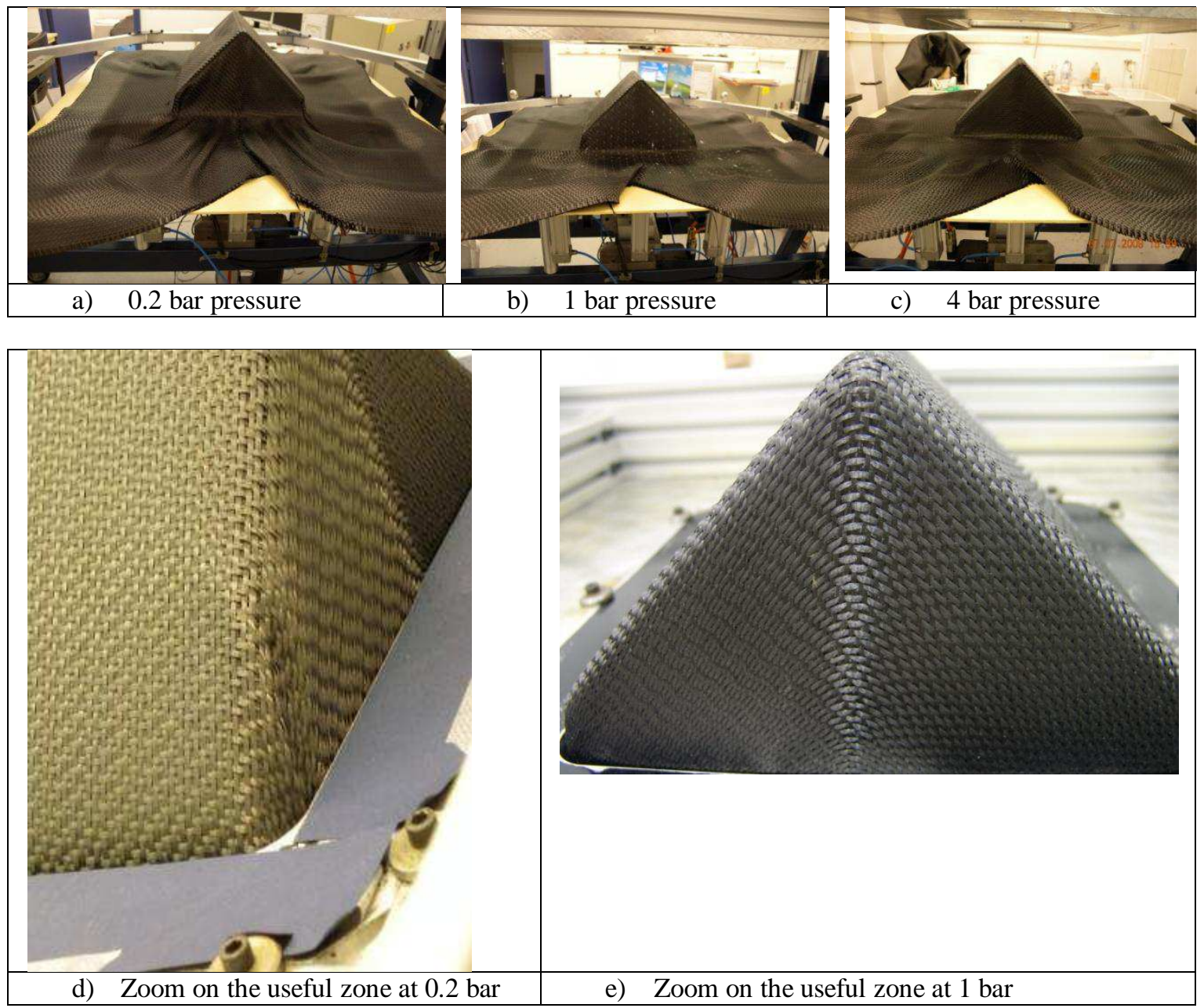

Fig 9 : external view of the prismatic shape of a carbon interlock weave.

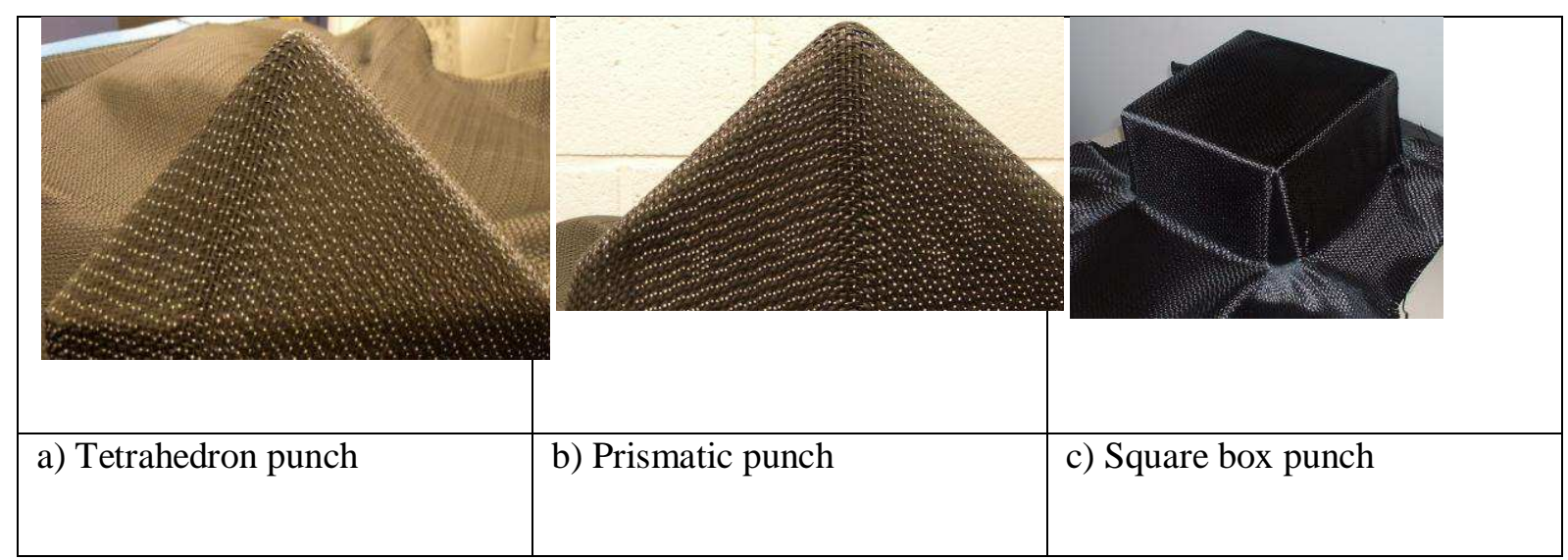

Fig 10 : Drawing of a carbon interlock weave with three different punches (1 bar pressure) 


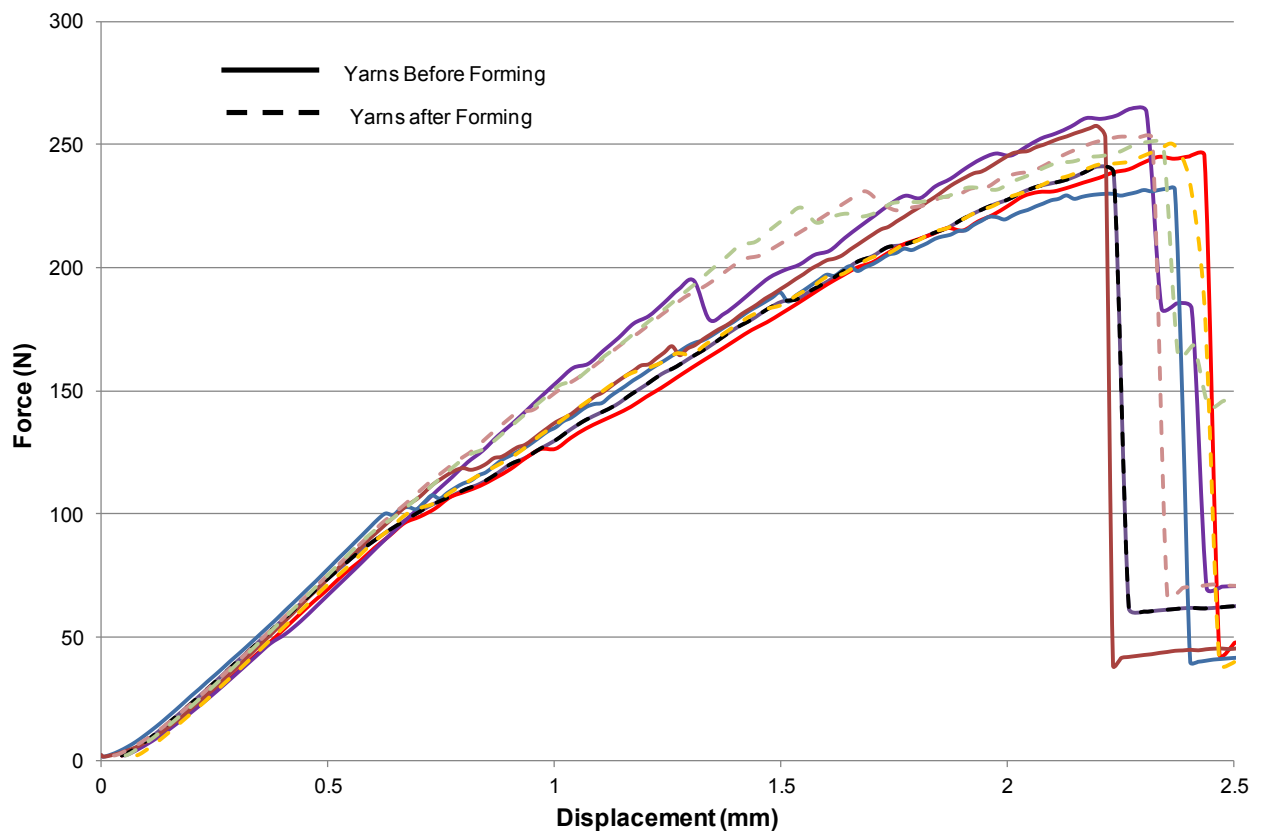

Fig 11 : Tensile behaviour of yarns extracted from the dry fabric before and after shaping

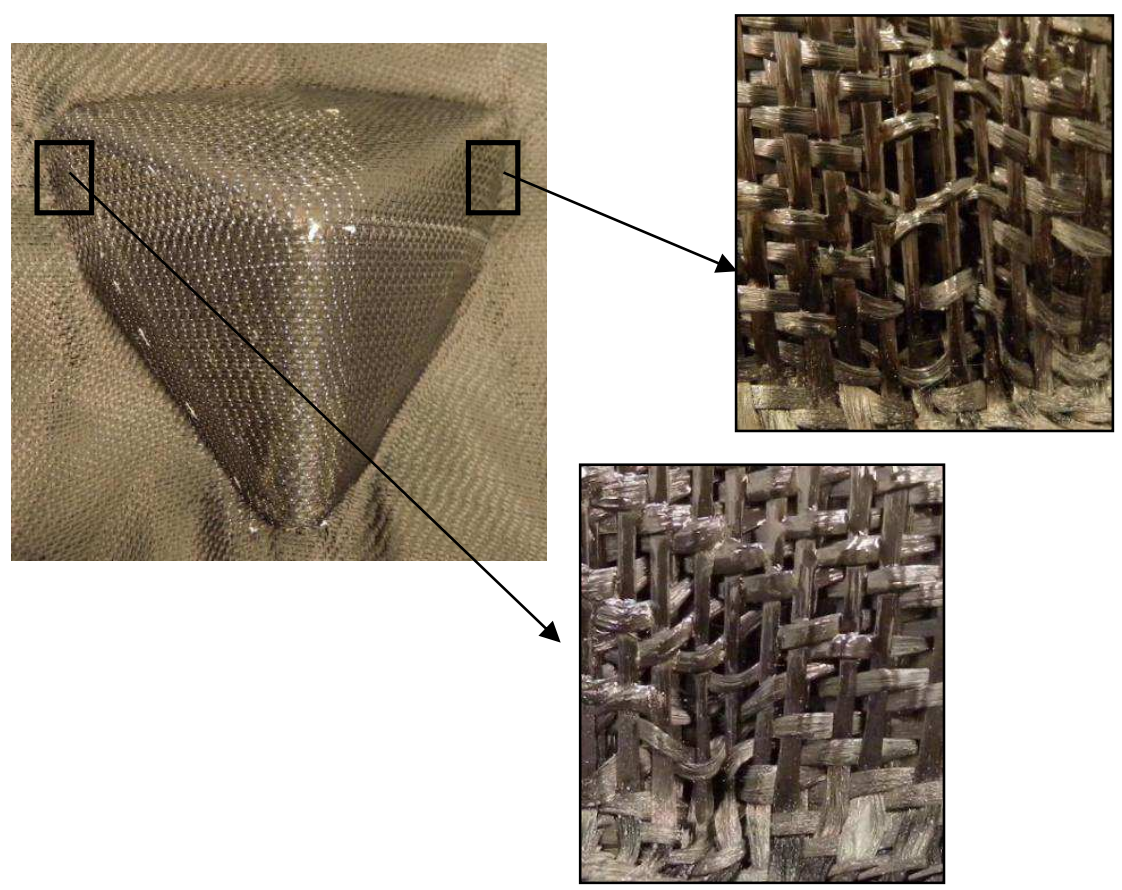

Fig 12 : Tetrahedron drawing of the interlock weave with 4 bar pressure 


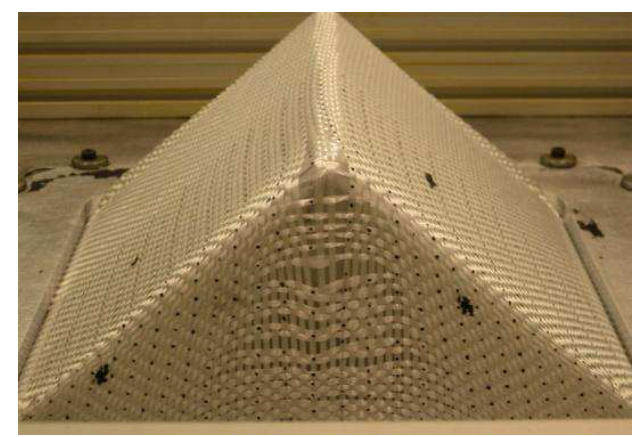

Fig 13 : The "weave pattern heterogeneity" phenomenon on the prismatic shape of a glass plain weave fabric under 1 bar pressure.
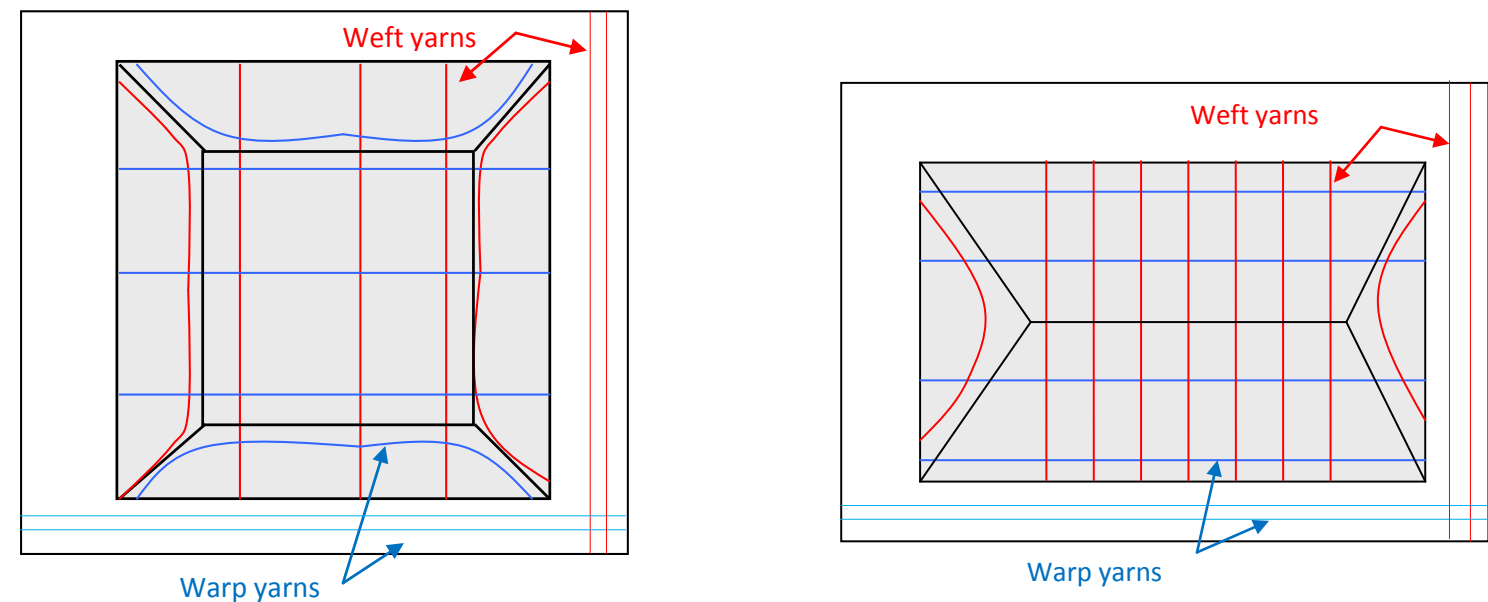

a) Square box shape

b) Prismatic shape

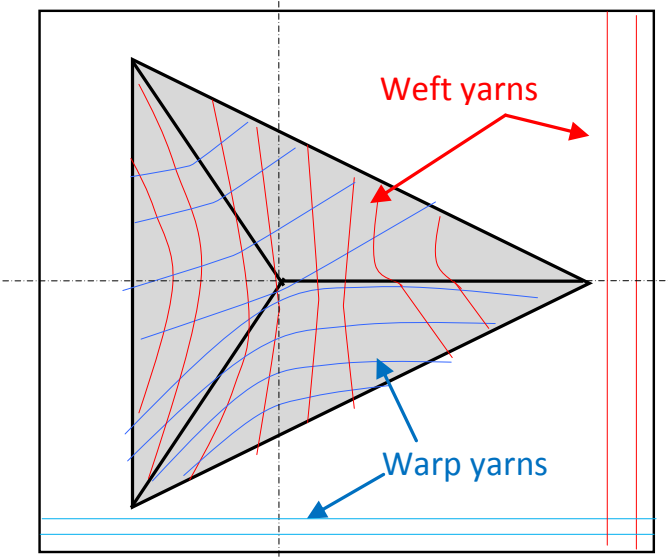

c) Tetrahedron shape

Fig 14: Yarns orientation after forming for the three considered shapes. 


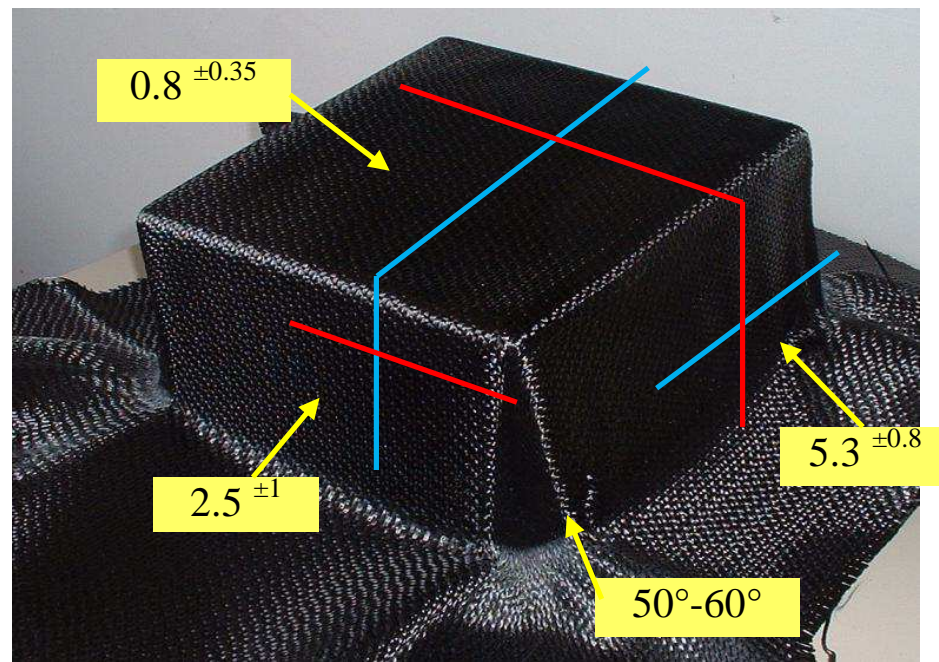

Fig 15: Shear angles after a square box forming of the interlock weave. Red: weft yarns; Blue: warp yarns; yellow: shear zones.

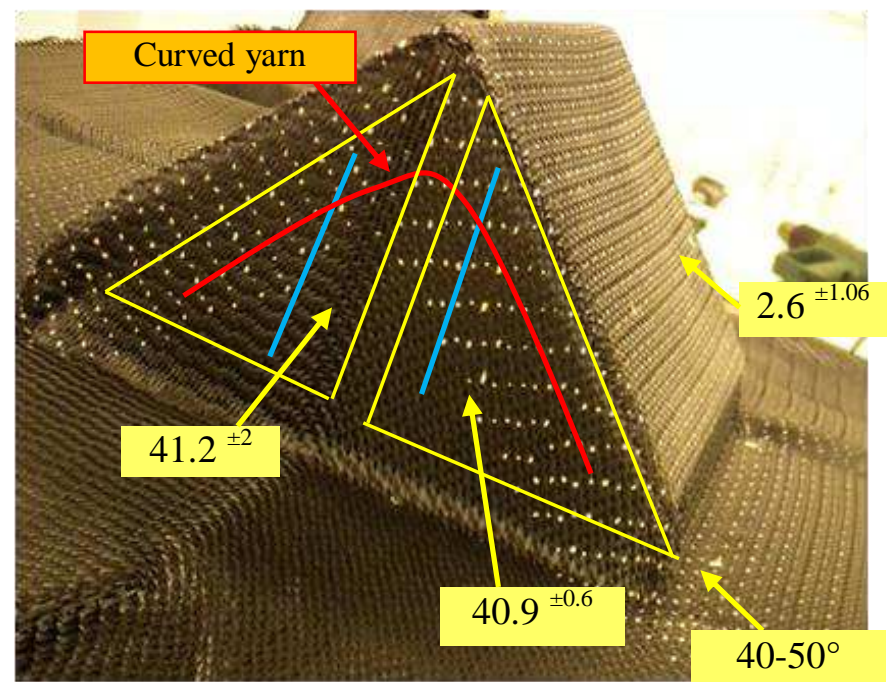

Fig 16: Shear angles after a prismatic forming of the interlock weave. Red: weft yarns; Blue: warp yarns; yellow: shear zones. 


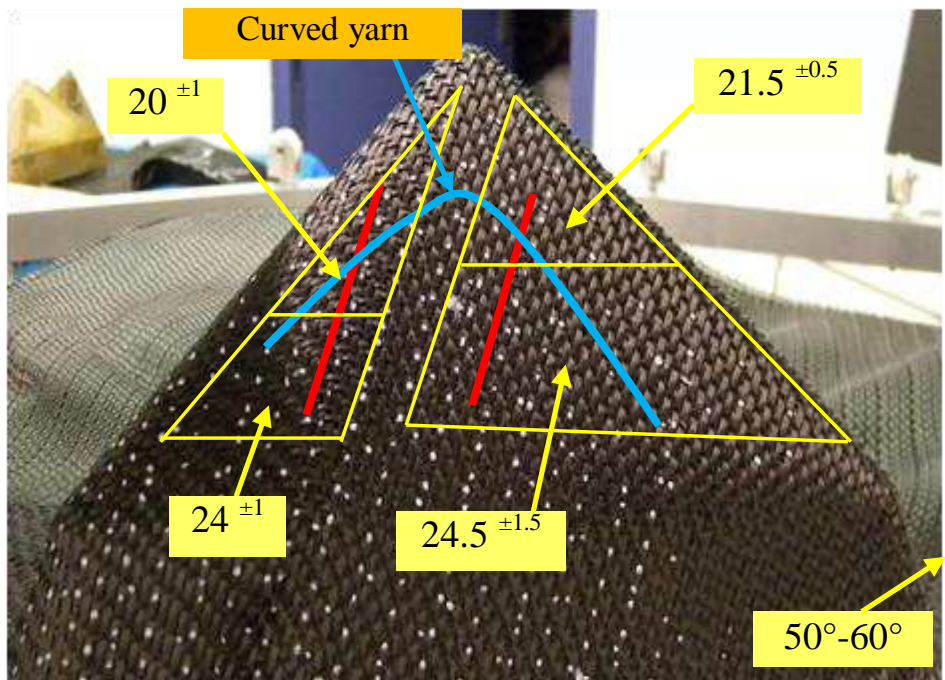

Fig 17: Shear angles after a tetrahedron forming of the interlock weave. Red: weft yarns; Blue: warp yarns; yellow: shear zones.

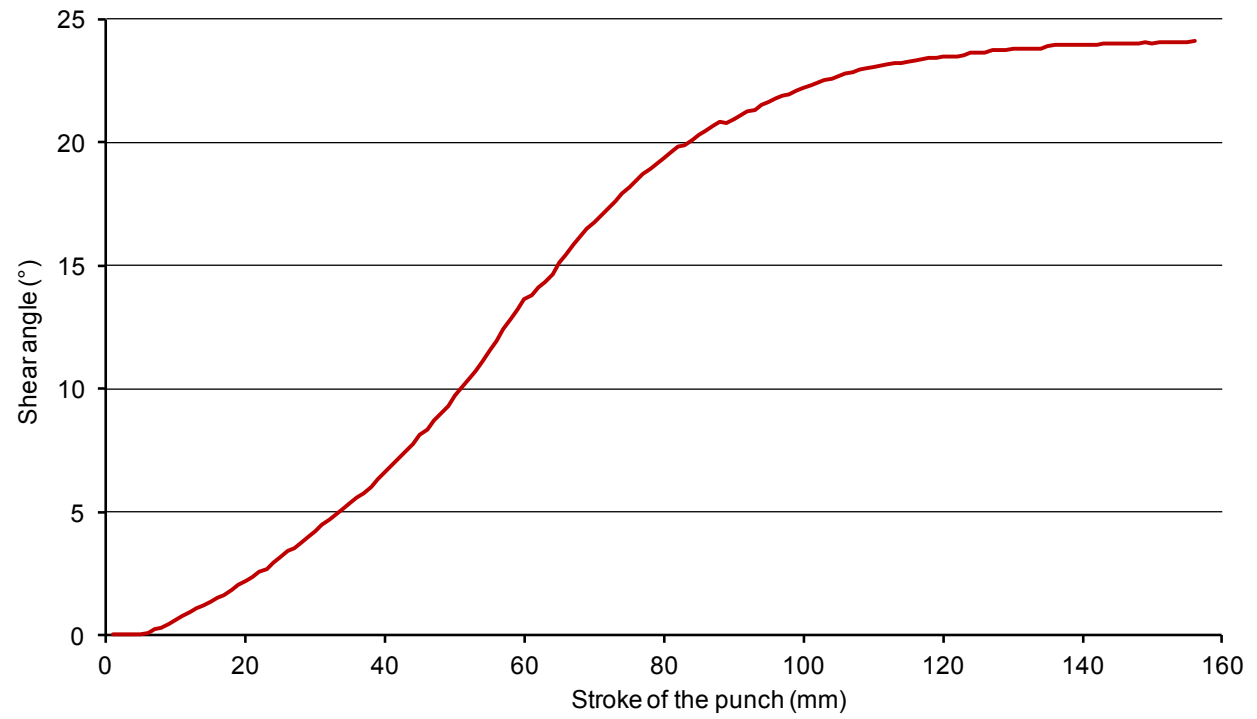

Fig 18: Shear angle evolution during the tetrahedron forming of the interlock weave. 


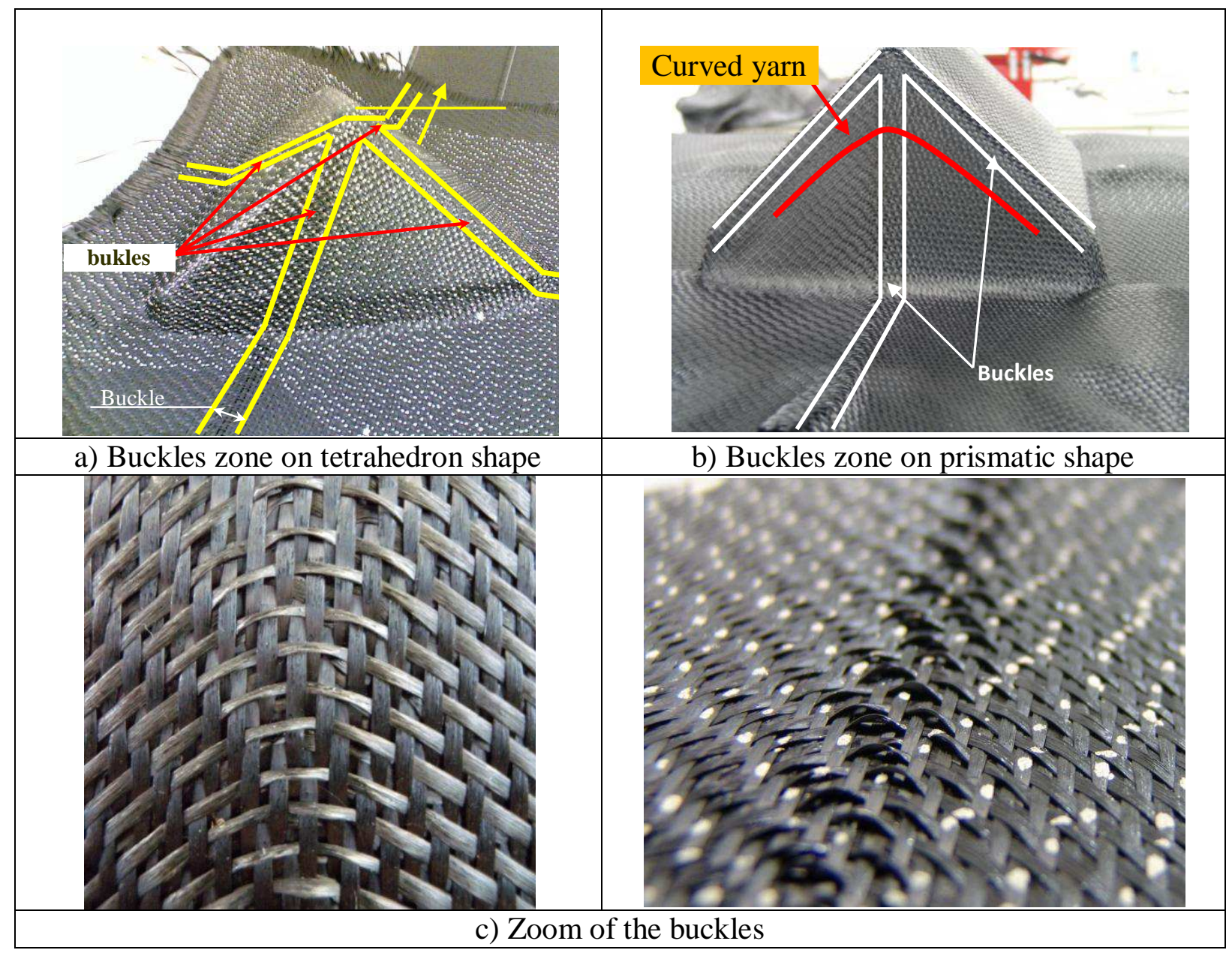

Fig 19: The out of plane buckling default at the end of the tetrahedron and prismatic forming of G1151 ${ }^{\circledR}$ layer. 